\title{
Erratum to: Does Corporate Governance Enhance Common Interests of Shareholders and Primary Stakeholders?
}

\author{
Ninghua Zhong ${ }^{1} \cdot$ Shujing Wang ${ }^{2} \cdot$ Rudai Yang $^{3}$
}

Published online: 17 October 2016

(C) Springer Science+Business Media Dordrecht 2016

\section{Erratum to: J Bus Ethics}

DOI 10.1007/s10551-015-2702-5

The name of the third author was misspelled as Ruidai Yang in above mentioned article. The name of the author has been corrected to Rudai Yang in the online version.

The online version of the original article can be found under doi:10.1007/s10551-015-2702-5.

Shujing Wang

wangshujing@sfu.edu.cn

Ninghua Zhong

ninghua.zhong@gmail.com

Rudai Yang

rdyang@pku.edu.cn

1 School of Economics and Management, Tongji University, 1239 Siping Road, Shanghai 200092,

People's Republic of China

2 School of Finance, Shanghai Lixin University of Accounting and Finance, Shanghai, People's Republic of China

3 School of Economics, Peking University, Beijing, People's Republic of China 